\title{
PENENTUAN KOEFISIEN RESTITUSI BENDA MENGGUNAKAN METODE VIDEO TRACKING
}

\author{
Silvia Triana Juita ${ }^{1}$, Maria Septelniati Seko ${ }^{2}$, Agustina Yunita Seku ${ }^{3}$, Sriwati \\ Ahmad $^{4}$, Richardo Barry Astro ${ }^{5}$ \\ Program Studi Pendidikan Fisika, FKIP, Universitas Flores \\ e-mail: silviatrianajuita28@gmail.com
}

\begin{abstract}
ABSTRAK
Telah dilakukan penelitian tentang tumbukan lenting sebagian pada bulan Maret 2020 di Bengkel Fisika dasar program studi Pendidikan Fisika Universitas Flores. Penelitian ini bertujuan untuk mengetahui koefisien restitusi beberapa benda seperti bola tenis dan bola pingpong terhadap lantai dengan metode video tracking. Penelitian dilakukan dengan melepaskan bola tenis dan bola pingpong dari ketinggian sekitar satu meter. Kegiatan ini direkam menggunakan kamera android dengan pengaturan 30 framerate per second (30 fps). Pengukuran dilakukan secara berulang untuk tiap benda guna mendapatkan hasil yang akurat. Video rekaman selanjutnya dianalisis menggunakan aplikasi Tracker Video Analysis. Data hasil analisis video antara lain berupa grafik pergerakan benda tiap waktu dan ketinggian pantulan benda. Berdasarkan data tinggi pantulan benda diperoleh koefisien tumbukan bola tenis terhadap lantai keramik sebesar 0,787 , dan bola pingpong terhadap lantai keramik sebesar 0,795 .
\end{abstract}

Kata Kunci : Tumbukan, Koefisien Restitusi, Video Tracking.

\section{ABSTRACT}

A partial collision study was conducted in March 2020 in a basic physics workshop at the University of Flores Physics Education Study Program. This study aims to determine the coefficient of restitution of some objects such as tennis balls and ping-pong balls on the floor with the video tracking method. The study was conducted by releasing tennis balls and ping pong balls from a height of one meter. This activity was recorded using an android camera with a setting of 30 frames per second (30 fps). Measurements are made repeatedly for each object to get accurate results. The recorded video is then analyzed using the Tracker Video Analysis application. Video analysis results include, among other things, graphs of the movement of objects each time and the height of objects reflected. Based on the height of the object reflection data obtained the coefficient of the collision of tennis balls against the ceramic floor of 0,787; and ping-pong balls against the ceramic floor of 0,795 .

Keywords: Collision, Restitution Coefficient, Video Tracking. 


\section{PENDAHULUAN}

Fisika merupakan ilmu pengetahuan alam yang didasari oleh perkembangan sains dan teknologi. Sains merupakan suatu kegiatan yang dilakukan oleh setiap orang yang dihasilkan melalui konsep, prinsip, teori dan hukum (Yuliati \& Saputra, 2019). Keterampilan proses sains memiliki peranan penting dalam pembelajaran fisika yang dapat dilakukan melalui pemahaman konsep, proses penemuan dan penelitian (Siswono, 2017) dan (Habibbulloh \& Madlazim, 2014). Ilmu fisika memiliki peranan penting bagi kehidupan manusia karena banyak peristiwa sehari-hari yang melibatkan konsep fisika baik yang disadari maupun tanpa disadari (Amallia \& Yulianti, 2015). Salah satu sumber belajar fisika dapat diperoleh melalui peristiwa fisika sehari-hari maupun peristiwa fisika yang dikondisikan keadaannya agar diperoleh keadaan yang ideal untuk keperluan penelitian atau pembelajaran (Fadholi at al., 2018). Namun pengaplikasian fisika dan peristiwa alam yang bersifat nyata jarang dipelajari, terutama di level pendidikan menengah.

Banyak solusi telah dilakukan untuk memudahkan pelaksanaan pembelajaran fisika secara kontekstual, diantaranya penggunaan media kontekstual. Media kontekstual merupakan media pembelajaran dengan kegiatan belajarnya dikaitkan dengan kejadian nyata di dunia nyata. Salah satunya adalah fenomena tumbukan. Tumbukan merupakan salah satu materi yang terdapat dalam pelajaran fisika, yang merupakan peristiwa bertemunya dua buah benda. Tumbukan juga merupakan peristiwa yang terjadi pada benda dengan menggunakan konsep momentum (Resmiyanto, 2017). Tumbukan yang terjadi antara suatu benda memiliki gaya interaksi yang lebih besar dibandingkan pengaruh gaya luar yang ada (Sukmawati et al., 2018). Tumbukan terdiri atas tumbukan lenting sempurna, tumbukan lenting sebagian, dan tumbukan tidak lenting sama sekali.

\section{Tumbukan Lenting Sempurna}

Pada tumbukan lenting sempurna, terjadi peristiwa tumbukan dua buah benda yang bergerak berlawanan arah pada bidang datar. Tumbukan lenting sempurna terjadi ketika jumlah energi kinetik benda sebelum dan sesudah tumbukan bernilai tetap, sehingga diperoleh koefisien tumbukan atau koefisien restitusi $(e)$ sebesar satu. Pada peristiwa tumbukan lenting sempurna berlaku hukum kekekalan momentum dan hukum kekekalan energi kinetik (Mughny \& Rahmawati, 2016).

$$
\begin{aligned}
& E K_{1}+E K_{2}=E K_{1}^{\prime}+E K_{2}^{\prime} \\
& \frac{1}{2} m_{1} v_{1}^{2}+\frac{1}{2} m_{2} v_{2}^{2}=\frac{1}{2} m_{1}\left(v_{1}^{\prime}\right)^{2}+\frac{1}{2} m_{2}\left(v_{2}^{\prime}\right)^{2}
\end{aligned}
$$

Pada hukum kekekalan momentum linear berlaku:

$$
m_{1} v_{1}+m_{2} v_{2}=m_{1} v_{1}^{\prime}+m_{2} v_{2}^{\prime}
$$

\section{Tumbukan Lenting Sebagian}

Konsep pada tumbukan lenting sebagian dapat diterapkan pada bola yang dipantulkan terhadap lantai. Pada peristiwa tersebut hukum kekekalan mekanik tidak berlaku karena selama tumbukan energi kinetik benda semakin berkurang. Energi kinetik sebelum 
tumbukan lebih besar dibandingkan energi kinetik sesudah tumbukan. Dengan demikian koefisien restitusi tumbukan lenting sebagian bernilai antara nol dan satu $(0<\mathrm{e}<1)$ (Mughny \& Rahmawati, 2016).

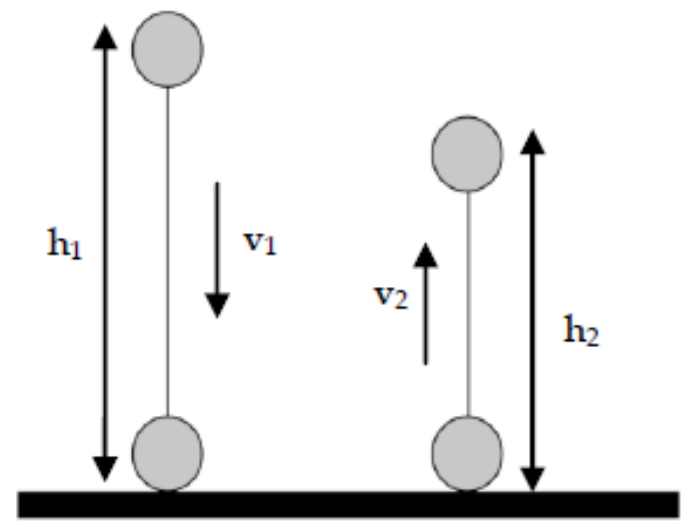

Gambar 1. Peristiwa tumbukan lenting sebagian pada bola (Mughny \& Rahmawati, 2016)

Gambar 1 menunjukkan sebuah bola mengalami gerak jatuh bebas dari ketinggian $\mathrm{h}_{1}$ terhadap lantai. Tumbukan antara bola dengan lantai merupakan jenis tumbukan lenting sebagian. Hal ini dapat terlihat dari tinggi pantulan $\mathrm{h}_{2}$ yang lebih kecil dibanding tinggi mula-mula. Pada tumbukan lenting sebagian terdapat koefisien restitusi. Koefisien restitusi (e) adalah tingkat kelentingan suatu tumbukan yang dapat dinyatakan sebagai sebuah nilai. Jika sebuah bola dijatuhkan dari ketinggian $\mathrm{h}_{1}$ dan terjadi tumbukan pertama antara bola dengan lantai, maka tinggi yang diperoleh adalah $\mathrm{h}_{2}$ dan terjadi tumbukan lagi yang tingginya menjadi $h_{3}$, dan seterusnya, sehingga besarnya koefisien restitusi untuk pantulan bola dapat menggunakan persamaan berikut (Sunard \& Gamayel, 2019):

$$
e=\sqrt{\frac{h_{2}}{h_{1}}}=\sqrt{\frac{h_{2}}{h_{1}}}
$$

\section{Tumbukan Tidak Lenting Sama Sekali}

Tumbukan tidak lenting sama sekali terjadi peristiwa menyatunya dua buah benda yang akan bergerak secara bersamaan dan memiliki kecepatan yang sama setelah tumbukan. Sehingga tumbukan tidak lenting sama sekali dari dua buah benda selalu melibatkan adanya kehilangan energi kinetik dari sistem. Pada tumbukan ini besarnya nilai koefisien restitusi $e$ adalah nol. Untuk menghitung besar koefisien restitusi dapat dihitung menggunakan persamaan (Anjani et al., 2018):

$$
e=-\frac{v_{2}^{\prime}-v_{1}^{\prime}}{v_{2}-v_{1}}
$$

Keterangan:

$e \quad=$ koefisien restitusi

$v_{1}=$ kecepatan benda 1 sesaat sebelum tumbukan

$v_{2}=$ kecepatan benda 2 sesaat sebelum tumbukan

$v^{\prime}{ }_{1}=$ kecepatan benda 1 sesaat setelah tumbukan

$v_{2}^{\prime}=$ kecepatan benda 2 sesaat setelah tumbukan 
Pada eksperimen penentuan koefisien restitusi, umumnya pengamatan parameter gerak masih dilakukan secara manual. Posisi tinggi pantulan mengandalkan kecermatan pengamat yang kemudian diukur menggunakan mistar. Proses tersebut sangat rentan akan kesalahan baik berupa ketelitian alat ukur maupun subjektivitas pengamat terutama jika data yang dikumpulkan lebih dari satu pantulan. Salah satu cara meminimalisir kesalahan tersebut ialah penggunakan teknologi untuk menggantikan peran pengamat berupa aplikasi video Tracker (Astro et al., 2018). Tracker adalah perangkat lunak analisis video dan pemodelan. Tracker dikembangkan oleh Open Source Physics (OSP) menggunakan kerangka kerja Java. Fitur yang tersedia termasuk pelacakan objek dengan posisi, kecepatan dan percepatan (Wijayanto \& Susilawati, 2013). Video tracker dapat digunakan sebagai media pembelajaran di kelas untuk menganalisis berbagai perbedaan gerak lurus berubah beraturan seperti gerak vertikal ke bawah, dan gerak vertikal ke atas. Tracker dapat membantu kita untuk menganalisis suatu benda yang terdapat dalam suatu video dengan mengikuti gerak benda yang ditandai dengan jejak arah gerak benda tersebut (Fitriyanto \& Sucahyo, 2016). Aplikasi video tracker ini juga dimanfaatkan dalam eksperimen tumbukan untuk memperoleh data hasil analisis koefisien restitusi tumbukan.

\section{METODE}

Adapun tujuan dari penelitian ini adalah untuk menentukan koefisien tumbukan beberapa benda menggunakan video tracking. Penelitian ini dilaksanakan di Bengkel Fisika program studi Pendidikan Fisika Universitas Flores menggunakan bola tenis dan bola pingpong.

\section{Alat dan bahan}

1. Bola pingpong dan bola tenis

2. Mistar $60 \mathrm{~cm}$ (1 buah)

3. Kertas sebagai latar untuk penulisan skala kalibrasi

4. Kamera oppo A37f

5. Aplikasi software tracker video analysis

\section{Prosedur}

1. Ketinggian awal eksperimen yaitu 1 meter yang diukur menggunakan mistar.

2. Benda berbentuk bola (tenis dan pingpong) di jatuhkan dari ketinggian awal sekitar 1 meter

3. Mengulang pengambilan data sebanyak 5 kali

4. Eksperimen direkam menggunakan kamera oppo A37f,

5. Analisis video menggunakan aplikasi video tracker

6. Data hasil analisis dihitung menggunakan persamaan pada tumbukan lenting sebagian untuk memperoleh koefisien restitusi. 


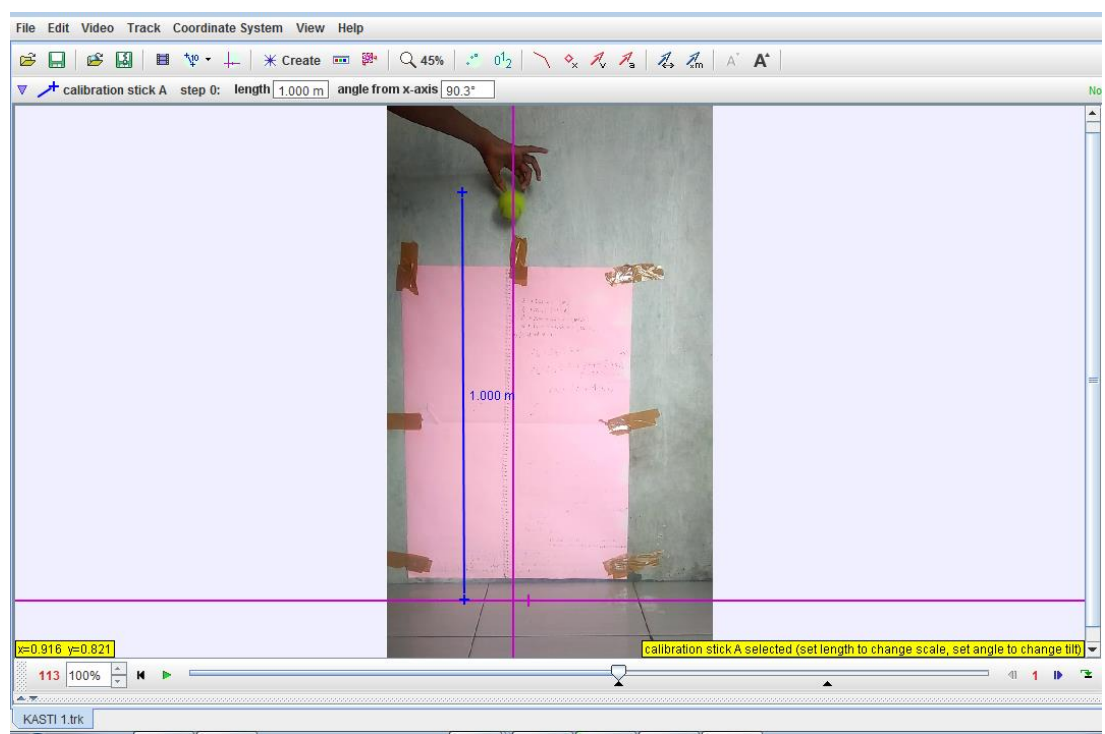

Gambar 2. Proses tracking video

\section{HASIL DAN PEMBAHASAN}

Berdasarkan penelitian yang telah dilakukan oleh (Utari \& Prima, 2019) bahwa tracker memiliki tujuan untuk menganalisis kecepatan benda sebelum dan sesudah tumbukan, sehingga dapat diketahui tingkat kekerasan permukaan benda dapat mempengaruhi tingkat kesempurnaan tumbukan. Pada eksperimen ini bola dilepaskan dari ketinggian satu meter $\left(\mathrm{h}_{1}\right.$ atau $\left.\mathrm{y}_{1}\right)$ dan jatuh menumbuk lantai keramik. Pemantulan yang diamati adalah tinggi pantulan pertama $\left(\mathrm{h}_{2}\right.$ atau $\left.\mathrm{y}_{2}\right)$, pantulan kedua $\left(\mathrm{h}_{3}\right.$ atau $\left.\mathrm{y}_{3}\right)$ dan pantulan ketiga ( $\mathrm{h}_{4}$ atau $\mathrm{y}_{4}$ ). Eksperimen ini dilakukan sebanyak 5 kali untuk memperoleh data yang valid. Grafik posisi bola hasil analisis video menggunakan aplikasi tracker ditunjukkan pada Gambar 3 dan 4.

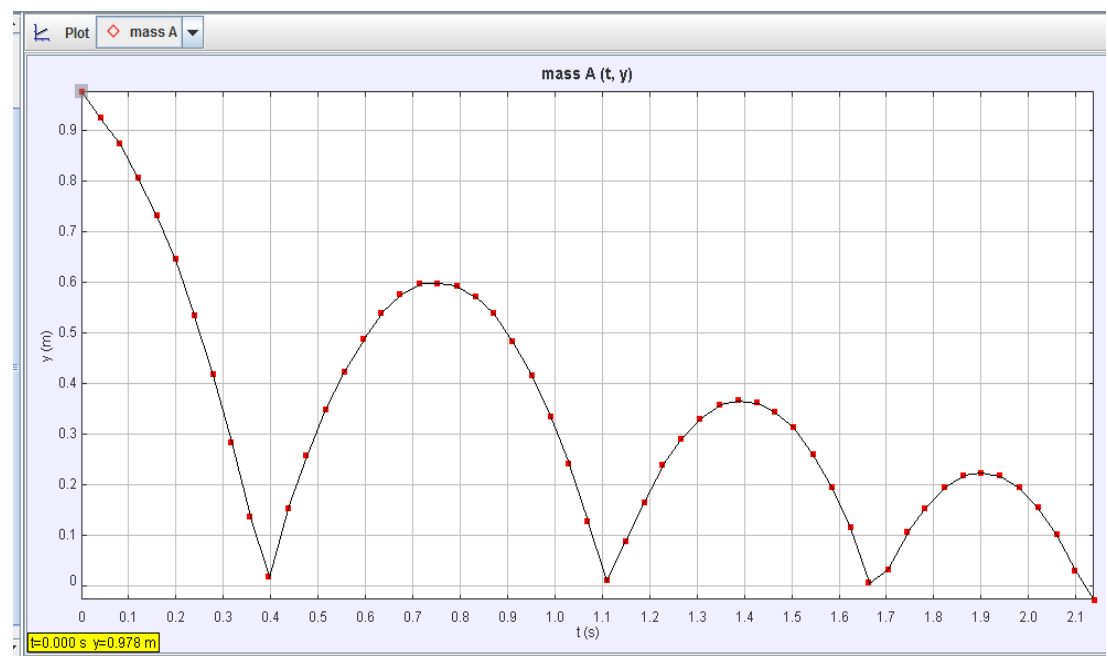

Gambar 3. Grafik posisi bola tenis terhadap waktu (Eksperimen ke-4) 


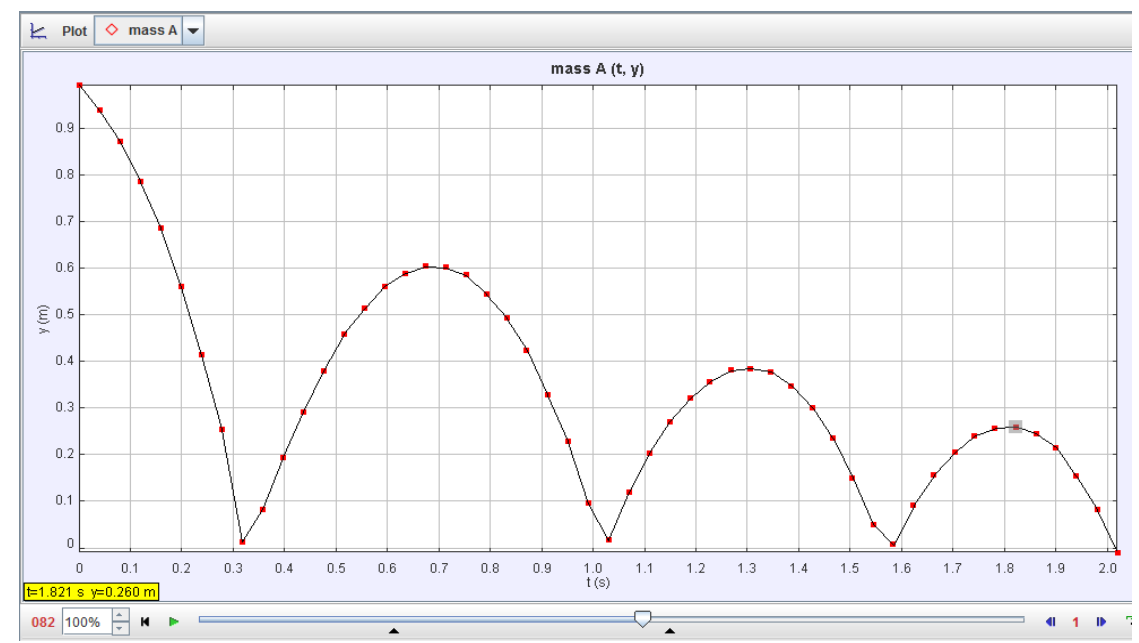

Gambar 4. Grafik posisi bola pingpong terhadap waktu (Eksperimen ke-4)

Berdasarkan Gambar 3 dan 4, terlihat bahwa kedua benda mengalami peristiwa tumbukan lenting sebagian. Hal ini terlihat dari ketinggian pantulan yang cenderung mengecil dibandingkan tinggi mula-mula. Nilai koefisien restitusi untuk masing-masing benda berdasarkan persamaan (4) disajikan Tabel 1 dan Tabel 2. Pada percobaan yang dilakukan(Zainuddin et al., 2017) untuk menentukan koefisien restitusi tumbukan lenting sebagian menggunakan persamaan $\mathrm{e}=\sqrt{\frac{\mathrm{y} 2}{\mathrm{y} 1}}=\sqrt{\frac{y 1}{y}}$

Tabel 1. Tinggi pantulan dan koefisien restitusi bola tenis

\begin{tabular}{|c|c|c|c|c|c|c|c|c|}
\hline \multirow{2}{*}{$\begin{array}{c}\text { Eksperimen } \\
\text { ke- }\end{array}$} & \multicolumn{4}{|c|}{ Ketinggian } & \multicolumn{4}{c|}{ Koefisien restitusi } \\
\cline { 2 - 9 } & $\boldsymbol{h}_{\boldsymbol{I}}(\mathbf{m})$ & $\boldsymbol{h}_{\mathbf{2}}(\mathbf{m})$ & $\boldsymbol{h}_{\mathbf{3}}(\mathbf{m})$ & $\boldsymbol{h}_{\mathbf{4}}(\mathbf{m})$ & $\sqrt{\frac{\boldsymbol{h}_{\mathbf{2}}}{\boldsymbol{h}_{\mathbf{1}}}}$ & $\sqrt{\frac{\boldsymbol{h}_{\mathbf{3}}}{\boldsymbol{h}_{\mathbf{2}}}}$ & $\sqrt{\frac{\boldsymbol{h}_{\mathbf{4}}}{\boldsymbol{h}_{\mathbf{3}}}}$ & $\overline{\boldsymbol{e}}$ \\
\hline 1 & 0,966 & 0,607 & 0,369 & 0,232 & 0,793 & 0,780 & 0,793 & 0,788 \\
\hline 2 & 0,998 & 0,620 & 0,379 & 0,231 & 0,788 & 0,782 & 0,781 & 0,784 \\
\hline 3 & 0,953 & 0,600 & 0,371 & 0,231 & 0,793 & 0,786 & 0,789 & 0,790 \\
\hline 4 & 0,985 & 0,618 & 0,385 & 0,242 & 0,792 & 0,789 & 0,793 & 0,791 \\
\hline 5 & 0,978 & 0,598 & 0,366 & 0,223 & 0,782 & 0,782 & 0,781 & 0,782 \\
\hline Rata-Rata & $\mathbf{0 , 9 7 6}$ & $\mathbf{0 , 6 0 9}$ & $\mathbf{0 , 3 7 4}$ & $\mathbf{0 , 2 3 2}$ & $\mathbf{0 , 7 9 0}$ & $\mathbf{0 , 7 8 4}$ & $\mathbf{0 , 7 8 7}$ & $\mathbf{0 , 7 8 7}$ \\
\hline
\end{tabular}

Tabel 2. Tinggi pantulan dan koefisien restitusi bola pingpong

\begin{tabular}{|c|c|c|c|c|c|c|c|c|}
\hline \multirow{2}{*}{$\begin{array}{c}\text { Eksperimen } \\
\text { ke- }\end{array}$} & \multicolumn{4}{|c|}{ Ketinggian } & \multicolumn{4}{c|}{ Koefisien restitusi } \\
\cline { 2 - 9 } & $\boldsymbol{h}_{\boldsymbol{I}}(\mathbf{m})$ & $\boldsymbol{h}_{\mathbf{2}}(\mathbf{m})$ & $\boldsymbol{h}_{\mathbf{3}}(\mathbf{m})$ & $\boldsymbol{h}_{\boldsymbol{4}}(\mathbf{m})$ & $\sqrt{\frac{\boldsymbol{h}_{\mathbf{2}}}{\boldsymbol{h}_{\mathbf{1}}}}$ & $\sqrt{\frac{\boldsymbol{h}_{\mathbf{3}}}{\boldsymbol{h}_{\mathbf{2}}}}$ & $\sqrt{\frac{\boldsymbol{h}_{\mathbf{4}}}{\boldsymbol{h}_{\mathbf{3}}}}$ & $\overline{\boldsymbol{e}}$ \\
\hline 1 & 0,990 & 0,578 & 0,375 & 0,248 & 0,764 & 0,805 & 0,813 & 0,794 \\
\hline 2 & 0,994 & 0,592 & 0,377 & 0,253 & 0,772 & 0,798 & 0,819 & 0,796 \\
\hline 3 & 0,973 & 0,586 & 0,369 & 0,246 & 0,776 & 0,794 & 0,816 & 0,795 \\
\hline 4 & 0,994 & 0,602 & 0,385 & 0,260 & 0,778 & 0,800 & 0,822 & 0,800 \\
\hline 5 & 0,994 & 0,614 & 0,390 & 0,241 & 0,786 & 0,797 & 0,786 & 0,790 \\
\hline Rata-rata & $\mathbf{0 , 9 8 9}$ & $\mathbf{0 , 5 9 4}$ & $\mathbf{0 , 3 7 9}$ & $\mathbf{0 , 2 5 0}$ & $\mathbf{0 , 7 7 5}$ & $\mathbf{0 , 7 9 9}$ & $\mathbf{0 , 8 1 1}$ & $\mathbf{0 , 7 9 5}$ \\
\hline
\end{tabular}


Data tumbukan lenting sebagian yang terlihat pada Tabel 1 dan Tabel 2 menunjukkan perbedaan nilai ketinggian pantulan maupun koefisien restitusi meskipun tidak signifikan. Untuk tumbukan antara bola tenis terhadap lantai terlihat ketinggian pantulan pada kelima data menunjukkan tren yang cukup konstan. Selisih ketinggian pantulan terhadap nilai rata-rata terbesar adalah $0,011 \mathrm{~m}$ terjadi pada data eksperimen ke-2 dan ke-5 untuk pantulan pertama $\left(h_{2}\right)$, dan juga pada eksperimen ke-4 untuk pantulan kedua $\left(h_{3}\right)$. Namun demikian perbedaan tersebut tidak mempengaruhi koefisien restitusi secara signifikan. Dari kelima data eksperimen dan tiga perbandingan ketinggian pantulan, diperoleh koefisien restitusi antara bola tenis dan lantai dengan nilai rata-rata 0,787.

Pada Tabel 2, ketinggian pantulan pada kelima data tumbukan antara bola pingpong terhadap lantai menunjukkan tren yang cukup konstan. Selisih ketinggian pantulan terhadap nilai rata-rata terbesar bola pingpong adalah $0,020 \mathrm{~m}$ terjadi pada data eksperimen ke-5 untuk pantulan pertama $\left(h_{2}\right)$. Namun eksperimen dengan metode video tracking tetap menunjukkan nilai koefisien restitusi rata-rata antara bola pingpong terhadap lantai sebesar 0,795 .

Adapun perbedaan ketinggian pantulan dan koefisien restitusi pada eksperimen ini antara lain disebabkan oleh ketidakseragaman ketinggian awal benda. Ketinggian awal semula direncanakan sebesar 1 meter, namun setelah diolah menggunakan Tracker didapati nilai yang beragam meskipun perbedaan tersebut tidak signifikan. Penyebab lain yang dapat diidentifikasi adalah penggunaan kamera 30 fps yang belum cukup presisi memetakan posisi benda untuk tiap saat. Pada beberapa data percobaan terlihat bahwa frame tidak mampu menangkap posisi benda ketika mencapai ketinggian maksimum maupun saat benda tepat menumbuk lantai.

\section{PENUTUP}

Berdasarkan hasil eksperimen diperoleh nilai koefisien restitusi bola tenis terhadap lantai keramik sebesar 0,787 dan untuk bola pingpong diperoleh nilai 0,795. Eksperimen penentuan koefisien restitusi benda menggunakan metode video tracking menunjukkan nilai yang cukup konsisten sehingga dapat diterapkan pada eksperimen lanjutan dengan berbagai variasi benda dan ketinggian mula-mula. Namun demikian hal yang perlu diperhatikan adalah penggunaan kamera dengan resolusi dan framerate per second yang memadai sehingga proses tracking dapat dilakukan dengan baik.

\section{DAFTAR PUSTAKA}

Amallia, R., \& Yulianti, I. (2015). Penerapan Pendekatan Problem Posing untuk Meningkatkan Kemampuan Pemecahan Masalah pada Materi Sistem Persamaan Linear. In Seminar Nasional Matematika dan Pendidikan Matematika UNY (pp. 921928). Yogyakarta: Universitas Negeri Yogyakarta. https://doi.org/10.33654/math.v1i2.4

Anjani, R., Ariandini, S., Rizkianty, N., Fuadi, S., \& Pandu, M. (2018). Menentukan Momentum dan Koefisien Restitusi Benda Tumbukan Menggunakan Tracker Video Analyse. Journal of Teaching and Learning Physics, 3(2), 21-25. 
https://doi.org/10.15575/jotalp.v3i2.6554

Astro, R. B., Ratnaningsih, F., Asmarani, R., Aimon, H., \& Kurniasih, N. (2018).

Penentuan Momen Inersia Katrol pada Pesawat Atwood dengan Metode Video Tracking, 32-39.

Fadholi, L., Harijanto, A., \& Lesmono, A. D. (2018). Analisis Video Kejadian Fisika Dengan Software Tracker Sebagai Rancangan Bahan Ajar Momentum Dan Impuls. Jurnal Pembelajaran Fisika.

Fitriyanto, I., \& Sucahyo, I. (2016). Penerapan Software Tracker Video Analyzer Pada Praktikum Kinematika Gerak. Jurnal Inovasi Pendidikan Fisika(JIPF), 05(03), 9297.

Habibbulloh, M., \& Madlazim, M. (2014). Penerapan Metode Analisis Video Software Tracker Dalam Pembelajaran Fisika Konsep Gerak Jatuh Bebas Untuk Meningkatkan Keterampilan Proses Siswa Kelas X Sman 1 Sooko Mojokerto. Jurnal Penelitian Fisika Dan Aplikasinya (JPFA), 4(1), 15. https://doi.org/10.26740/jpfa.v4n1.p15-22

Mughny, A. A., \& Rahmawati, E. (2016). Design of Microcontroller-Based Momentum Conservation Experiment Kit. Jurnal Inovasi Fisika Indonesia, 05(03), 9-14.

Resmiyanto, R. (2017). Eksperimen konseptual tumbukan benda 1 dimensi dengan algodoo. Integrated Lab Journal, 95-100. Retrieved from http://ejournal.uinsuka.ac.id/pusat/integratedlab/article/download/1557/1260

Siswono, H. (2017). Analisis Pengaruh Keterampilan Proses Sains Terhadap Penguasaan Konsep Fisika Siswa. Momentum: Physics Education Journal, 1(2), 83. https://doi.org/10.21067/mpej.v1i2.1967

Sukmawati, S. S., Nursulistyo, E., \& Oktaviyanti, D. (2018). Pengembangan bahan ajar booklet untuk meningkatkan hasil belajar pokok bahasan momentum untuk siswa kelas X semester 2 SMAN 4 Yogyakarta. Prosiding Seminar Nasional Quantum, Pendiidkan Fisika UAD, 25, 53-60. Retrieved from http://seminar.uad.ac.id/index.php/quantum/article/view/234/190

Sunard, A., \& Gamayel, A. (2019). Pemanfaatan Pantulan Bola Karet sebagai Pemanen Energi pada Piezoelektrik. Prosiding Seminar Nasional Teknoka. https://doi.org/10.22236/teknoka.v3i0.2914

Utari, S., \& Prima, Ek. C. (2019). Analisis Hukum Kekekalan Momentum Model Tumbukan Kelereng dengan Gantungan Ganda menggunakan Analisis Video Tracker. Jurnal Pendidikan Fisika Dan Keilmuan, 5(2), 1-9. https://doi.org/10.2572/jpfk.v4i2.1814

Wijayanto, \& Susilawati. (2013). Rancangan Kinematika Gerak Menggunakan Alat Eksperimen Air Track Untuk Media Pembelajaran Fisika Berbasis Video. Jurnal Informatika Upgris (JIU), 132-139.

Yuliati, Y., \& Saputra, D. S. (2019). Pembelajaran Sains Di Era Revolusi Industri 4.0. Jurnal Cakrawala Pendas, 5(2), 167-171. https://doi.org/10.31949/jcp.v5i2.1389

Zainuddin, E. S., Mufida, D. H., \& Kencana, T. D. (2017). Penentuan Tinggi Bangunan Menggunakan Konsep Gerak Jatuh Bebas dan Koefisien Restitusi Tumbukan Untuk Menjelaskan Pembelajaran Mekanika, 290-294. 